\title{
Pedagogical Approaches for Online Environments
}

\author{
Luísa Miranda ${ }^{1}$, Carlos Morais ${ }^{1}$, Paulo Dias ${ }^{2}$ \\ ${ }^{1}$ Polytechnic Institute of Bragança, ${ }^{2}$ University of Minho, Portugal
}

\section{Introduction}

Assuming that Web-based Information and Communication Technologies are resources for support to the teaching and learning process, this article refers to a few pedagogical approaches which may be contextualized in methodologies supported by online learning environments, with the main aim of motivating reflection and the will to go deeper into strategies that can take advantage of those technological innovations which are fitted into pedagogical models allowing online education to be used and rendered profitable in service to training and educating people over the course of their lives.

Many are the intervening parties, the means and the contexts which could influence the formal teaching and learning process; however, we will point out that the main intervening parties include teachers and students, and the main means of supporting the teaching and learning process include information and communication technologies, most notably the Internet and the resources that are associated with it, by contextualizing such means and intervening elements in the act of teaching and learning in learning environments, in which we foster interactions of a varied nature conducive to the teaching and learning process and, consequently, to knowledge-building.

Discussion can be focused on creating models for online education which connect the intervening elements with the support means and the relationships between both, as structures are defined that can respond to educational objectives and perspectives. With a constructivist model as a reference, student-centered teaching and learning strategies are upheld and, as such, we seek to build learning environments that will embody such strategies.

The task of building of a student-centered online learning environment is quite complex. According to Palloff and Pratt, in order for an online learning environ- 
ment to be truly student-centered, teachers need to understand who the students are and how they learn, to be attentive to topics students bring to the learning environment and to the type of support they need, and to respect students' role in the learning process [1].

In the field of online education, we notice a continuous debate going on about potential students who feel drawn to this method of teaching. It has been confirmed that the online student is no longer just adults - attending traditional correspondence courses aiming to bring about professional development - , but also young people. This fact has aroused the interest of a large number of institutions, which offer courses in the form of blended learning models, a combination of face-to-face and online learning systems, or totally online, which offer flexible and choice options that are more and more adaptable to the objectives and interests of students from the various age groups. Online education attracts people of all ages and cultures, who live anywhere in the world.

We will be dealing with several topics for reflection on the pedagogical approaches for online learning environments; in particular, such topics will include: contextualizing online learning environments, learning metaphors, most prominently those bearing the following designations: acquisition metaphor, participation metaphor, and metaphor for creating knowledge, as well as the pedagogical approaches of Duart and Sangrà and that of Terry Anderson for developing online education.

\section{Contextualizing online learning environments}

Given the potential of Web-supported resources for creating online learning environments, we consider that the learning environment concept, on top of physical and time-related areas, involves the availability of resources and strategies based on sharing and joint collaboration between the intervening parties involved in the educational process.

We can consider that online environments constitute an institutionalized teaching and learning context where the main intervening parties in the knowledgebuilding process, both student and teacher, are not present in the same physical area at the same time, and the development of communication and interaction is supported by technological resources.

Overcoming physical distances and bringing people closer together, in psychological terms, in the way they feel, work or carry out projects in a collaborative and shared manner, all constitute aims to be achieved as part of the teaching and learning process, by fostering pedagogical approaches that ensure efficiency and quality in learning and teaching. We have witnessed the development of pedagogy that is suited to correspondence teaching which has been interpreted and brought about distinct pedagogical models, as new technologies were being applied [2].

Courses in online environments can take on various formats, depending on the objectives with which they are used, the contexts in which they are implemented and the resources they make available. The diversity and amount of formats make 
it difficult to define a categorization that will be easily accepted. However, Mason points out a certain type, taking into account the use of the Internet, which ranges from courses making only secondary use of the Internet to courses that take place solely online, thus suggesting that the different models of online courses fit into one of the following categories:

- courses with irrelevant use of the Web: where the Web is an extra, optional resource for presenting materials or a means of communication;

- courses with integrated use: where a large part of the contents or activities is online;

- courses solely online: where the course contents and all communication with and support given to the student are online [3].

Online courses, generally the most visible side of online education, should, among other aspects, contribute toward improving learning environments, while fostering access to information and to communication, providing interaction between people and between local, regional, national and international institutions, with the aim of exchanging ideas, sharing cultures, projects, comparing problems and contributing toward solving them.

The type of online courses involves particular characteristics in pedagogical approaches that we intend to develop, although, as suggested by Morgado, despite the high number of online teaching experiences described in literature, it is not always possible to identify those conceptual models that guide such experiences [4].

In order to justify online courses in pedagogical theories, and especially in alluding to the development of online learning resources, Ally points out that the behaviorist, cognitivist and constructivist theories have contributed toward designing online resources and toward developing these same resources, and Ally also adds that behaviorist strategies can be used for teaching facts, cognitivist strategies for teaching principles and processes, and constructivist strategies for pinpointing problems in real-life situations and contextualizing learning [5].

The early computer-supported learning systems were designed on the basis of behaviorist approaches, generally oriented toward carrying out automated tasks and learning support services which rest on models for transmission of information. With the evolution of the potential associated with information and communication technologies and with the latest learning theories, we moved to models that regard the student as the center of learning.

In reply to concerns pertaining to the means used for teaching, learning and characterizing strategies that are conducive to fostering and acquiring knowledge, we will address a few of the characteristics of this problem, as they fit into learning metaphors. 


\section{Learning metaphors}

The concept of metaphor allows for various interpretations; however, it always represents an effort to create models that will make it easier to understand topics at the expense of concepts that are mastered.

In a pedagogical scenario with a wide variety of approaches, where there are theories that stress factors of a social, cultural or cognitive nature, Sfard points out two alternative means of understanding learning, giving them the designation of acquisition metaphor and participation metaphor [8].

The acquisition metaphor conceptualizes learning as an individual process for acquiring knowledge, and it can take on the form of a traditional receptive process or of an active and constructive process, how they stand up for constructivist theories that are concentrated on individual learning processes. Learning is considered in terms of knowledge structures which exist in the mind of each student, where the human mind can be considered to be a receptacle of knowledge, and learning is a process that enables the accumulation of knowledge in such a receptacle.

With the participation metaphor, learning is represented as a participation process in various cultural practices and in shared learning activities. In this regard, Palonen and Hakkarainen refer that the participation metaphor emphasizes the role of social communities in the learning and knowledge-building process [9]. Thus, the focus of learning is on activities and on doing things and not so much on knowledge as such, and it is also considered that learning is a process for participating in social scenarios [10].

Bartolomé notes that today's society emerges with the notion of participation, contrasted with the classic, one-directional discourse of the perfect class, the manual, the textbook and the classic interpretation of television or of audiovisual materials [11, p. 21]. The same author also suggests that technology evolves with regard to those pieces of equipment which made participation easier between the intervening parties in education, where the Internet and the resources associated with it were considered to be extremely important for such participation.

As a supplement to possible learning scenarios, and considering the two aforementioned metaphors, Paavola et al. suggest a third learning metaphor, which they call a metaphor for creating knowledge [12]. The same authors admit that, in terms of this metaphor, learning is analogous to research development models, in which new ideas, tools and practices are created in a collaborative manner and contribute toward enabling the original knowledge to be significantly enriched or transformed during the process. Thus, the focus of learning is not on the individual mind, as with the acquisition metaphor, nor is it on the social process, as with the participation metaphor, but, rather, in products of mediation as objects and practices developed in a collaborative manner during the learning process.

This learning approach as the creation of knowledge stresses the importance of the processes of mutual interaction and involvement in learning communities, by sharing in solving problems, in defining theories and in assessing results [13].

The creation and development of online learning environments, where learning can be fostered actively and in a collaborative way and based on the interaction 
Pedagogical Approaches for Online Environments

between the intervening parties is a challenge for every teacher. The response to such a challenge involves successive planning stages and making various choices before implementing the teaching and learning process.

Each learning environment has to be built while taking into account the way to approach each topic, which can be in terms of the student, the teacher, the type of interactions one wishes to foster, the support means one intends to use, the costs, or in terms of a variety of other forms, while maintaining, in each of these approaches, a coherent whole, which can comprise the structure and the possibility of implementing online courses supported by teaching institutions.

By pointing out pedagogical approaches showing mostly concern for the student, the role of the teacher or of the technology with the aim of building models, we are contributing toward building a theoretical field that can be the supporting basis for practices that are or that could be experienced in the field of online education. In this regard, we point out a few contributions from pedagogical approaches, developed by [14] and by [15] with implications to the theoretical field of online education.

\section{Pedagogical Approaches}

The development of online education has had quite an impact and has been accepted in institutions of Higher Learning. Since institutions of Higher Learning play an important role in preparing people for life within society and for work, we will not be able to implement pedagogical approaches starting from these institutions if we do not consider their curricula. Zabalza defines curriculum as: integrated formative project [16]. The same author considers: project - as something that has been thought out and designed in whole; formative - as this is aimed at improving the training of people taking part therein; integrated - because curricular projects need unity and internal coherence, and they should consist of a process characterized by a suitable internal structure and a continuity that is able to foster as much personal and vocational development as possible.

By associating pedagogical approaches with the notion of curriculum as an integrated formative project, this is then followed by the approach by Duart and Sangrà and that by Terry Anderson.

\section{Pedagogical approach by Duart and Sangrà}

By admitting that there is an increasing virtualization of teaching institutions, [14], they sought to build a model in which a methodological framework of such institutions is possible, by proposing conceptual models based on three variables: the means (the technology), the teacher and the student, which correspond, respectively, to models centered on means, teacher-centered models and studentcentered models. 
Models centered on means, resulting from the development of technology, are characterized by their centrality in the use of one of several technological tools. The student and the teacher, the main players involved in fostering the educational process, play a secondary role in this model. The teacher becomes a provider of contents, with the student becoming a user of those same contents, from which self-training should occur.

As an example of a model centered in means, we point out intranets, whose main function includes storing resources and making them available to students and teachers. Other distinctly emphatic situations in means consist of presenting contents using PowerPoint, or even providing contents in personal pages of teaching staff or on specific sites intended for particular subjects or courses from certain institutions. In each of the aforementioned cases, we notice that teachers very often simply place contents, which are received by students as a finished, readyto-use product.

Although this type of use of technologies can be regarded as yet another means for distributing contents, which is a little different from the means of making photocopies and giving them out to students, we feel that, on top of the contents shown, there is something more than making them available, both in the attitude of the teacher who looked for means to use for reaching students in a simple, innovative and convenient way, but also in the attitude of students who gradually feel they are obliged to use technologies which, although they start off as a simple act of consulting contents, quickly evolve to other formats and perspectives for using computer-related resources, such as in communicating and in presenting information research.

As suggested by Bartolomé, when a teacher fosters conditions in his students in order to use texts from the Internet, he/she is not limited to a simple change in information support, but is implementing a much more profound change into his/her teaching dynamics, where such a change affects the way we get to know the very essence of the knowledge we include [11]. The models centered on means, according to Duart and Sangrà, represent the classic self-training systems, which are modernized using the latest technologies [14].

Teacher-centered models refer us to classic models that are centered more on teaching than on learning, and in which the teacher is the main reference to the knowledge.

Student-centered knowledge is characterized by emphasis and centrality on the student. A student-centered context should also meet the needs of the teacher, the institution, society and, often, the group of students [15].

The independent nature provided by computer-supported technology favors student-centered teaching, thus enabling reflexive construction of knowledge based on the student's skills and objectives [18]. Creating a student-centered approach involves providing different students with different options.

By allowing for a certain centrality in the student's role, we will have to allow for a change in the teacher's role. The latter no longer holds down the exclusive role of transmission of knowledge, to become a facilitator and an orienting guide in the student's learning, as the teacher seeks to respect the student's learning 
runs. Thus, learning tasks should be mostly developed and oriented, in order to provide a response to the particular interests and concerns of each student.

The three models described are shown as being independent from one another, which gives the impression that it is possible to stress only one of the roles of the means, of the teachers or of the students, which is neither possible nor desirable. In this regard, we are of the opinion that the three models mentioned herein constitute a coherent whole in the teaching and learning context, although they can have different levels of use, depending on the context, the objectives and the strategy outlined for the teaching and learning process.

For Duart and Sangrà, it is possible to identify three variables in the aforementioned models, by showing them in a three-dimensional model in which the coordinates can be depicted so as to characterize each teaching institution on its way to virtualization. As adapted from the same authors, the following figure illustrates the afore-mentioned three-dimensional model [14].

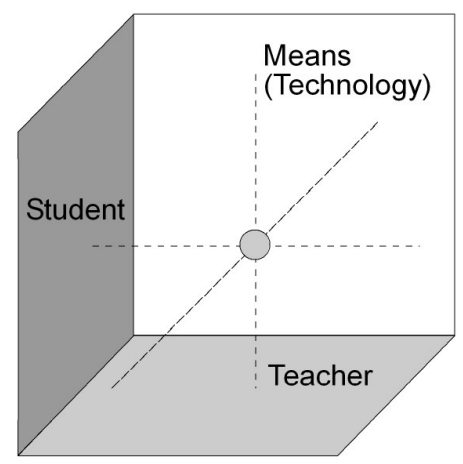

Fig. 1. Balance in a three-dimensional model, adapted from Duart and Sangrà (2000)

Among the advantages of the previous model, we point out the possibility of identifying main axes for pedagogical guidelines that we intend to define and implement at each institution, as we stress, on one hand, that students, teachers and the means are the fundamental elements of the educational context; on the other hand, this forces us to think about these three elements in a balanced way, for if we place too much emphasis on one of the axes, we might minimize the others and, consequently, not comply with a curriculum, which we defend as an integrated formative project.

Duart and Sangrà's contribution resulted in the construction of a theoretical organizational model, which can work as a generator of pedagogical models for online education, with a strong common basis, taking into account concerns with students, teachers and means, by fostering, at teaching institutions, combinations of these elements so as to be able to build suitable models of online learning environments that personalize them and respond to their education and training objectives and projects. 


\section{Pedagogical approach by Terry Anderson}

In considering the various teaching and learning formats that can be supported by the Web, Anderson suggests that it is premature to define an online learning theory [15]. However, he feels that the creation of a model is often the first step toward developing a theory. In this regard, he presents an online learning model in which we see a representation of the main variables included in building contexts and in developing learning experiences, where such variables include students and teachers, as well as interactions between them, and with contents.

The model put forth by Anderson rests on two pillars: independent learning, with roots in the field of distance education, and collaborative learning, with roots in the constructivist and socio-constructivist models [15]. The same author considers the Web potential important for building the pedagogical model, as he admits that quality learning should always be student-centered, in knowledge, in the community and in assessment, as we point out the importance of interactive formats.

The concept of interaction is complex, as it allows for various sizes and interpretation, which is sometimes considered to be synonymous with the dialogue taking place in the classroom, between the teacher and the students, or between the students themselves.

In distance education, the concept of interaction is shown by Moore in terms of the following relations: student-student, student-teacher and student-contents [19], where Anderson and Garrison (1998) (apud. [20]) added to these the interactive formats rendered by the relations: teacher-teacher, teacher-contents and contentscontents.

In this model, the teacher takes on a driving role, by intervening in creating and updating contents and in learning activities (teacher-content interaction), in the development of activities implemented in the learning community and in individual support to students (student-teacher interaction), in creating opportunities for the vocational development of teachers through communities where they can share problems, discuss ideas and outline teaching and learning strategies (teacherteacher interaction).

Content-content interaction is rendered in the way contents are programmed to interact with other contents via automated resources, as we point out the example of researching contents on the Internet using search engines, for it is through web agents that contents interact with one another in continuously operating networks, as we obtain search results almost instantly.

Within the context of innovation in the field of online education, the teacher will play a very important role, not just in using innovative interactive formats with the contents, but also as a participant on work teams that are responsible for defining learning objects that offer flexibility and the re-use of online resources that meet both individual and group needs of students.

The model we have just referred can be regarded as an open and flexible model providing the student and the teacher with the possibility of creating environments directed at learning contexts, ease of interaction and opportunities for developing both individual and collaborative work strategies. 
Pedagogical Approaches for Online Environments

As a summary, we point out that the Anderson model shows various ways of learning and teaching on the Web, as we stress the main variables involved in the teaching and learning process and the relationships between them, by putting in perspective the great importance to be attached to the interaction concept and to the various types of interaction that need to be favored and nurtured in the educational context.

\section{Final Considerations}

Online learning needs to respond more and more to the demand of different cultures, styles and motivations [5]. The approaches that have been presented help us to reflect on and build and a deeper vision of this very complex field. We point out the importance that the pedagogical aspect gains in online learning environments: while technological innovations help overcome the barriers of space and time, pedagogical approaches can contribute toward reducing psychological and cultural distances.

According to [13, p. 3] "learning activities supported by online environments on the Web are characterized by making training flexible and by developing interactions directed at learning processes, namely in collaborative aspects."

Pedagogical approaches pointed out in the text provide us with strong support elements for the development of online education: while the Duart and Sangrà approach implements a reference in an idealized teaching and learning area, made up of a three-dimensional model with the axes comprising the teacher, the student and the means, the Terry Anderson approach stresses not only the teacher, the student and the contents, but also the various types of relationships and interactions occurring in education contexts.

Because the information and communication society that we live in provides many abundant sources of information, it requires continuous consolidation and updating of the knowledge of citizens. Thus, online education can play an essential role, in order to monitor major changes in contemporary society, where the concept of lifelong education and training, constitutes a constant concern in the individual's sustained development, his/her knowledge and abilities in how to be active and to intervene in the collaborative construction of learning and knowledge networks.

\section{References}

1. Palloff R, Pratt K (2003) The virtual student: A profile and guide to working with online learners. Jossey-Bass Publishers, San Francisco

2. Pereira A, Mendes A, Mota J, Morgado L, Aires L (2003) Contributos para uma pedagogia do ensino online pós-graduado: Proposta de um modelo. Discursos: Novos rumos e pedagogia em ensino a distância 1: 39-52 
3. Mason R (2003) Models and methodologies in distance education. Discursos: Novos rumos e pedagogia em ensino a distância 1: 91-101

4. Morgado, L (2003) Ensino online: Contextos e interacções. Ph.D. thesis, Open University, Portugal

5. Ally M (2004) Foundations of educational theory for online learning. In: Anderson T, Elloumi $\mathrm{F}$ (eds.) Theory and practice of online learning. Athabasca University, Athabasca, pp 3-31

6. Sfard A (1998) On two metaphors for learning and the dangers of choosing just one. Educational Researcher 27: 4-13

7. Palonen T, Hakkarainen K (2000) Patterns of interaction in computer-supported learning: A social network analysis. In: Fishman B, O'Connor-Divelbiss S (eds.) Fourth International Conference of the Learning Sciences. NJ: Erlbaum, Mahwah, pp 334-339

8. Paavola S, Ilomäki L, Lakkala M, Hakkarainen K (2003) A framework for evaluating virtual learning materials through the three metaphors of learning. http://www.eun.org/eun.org2/eun/downloads/Three_metaphors.doc

9. Bartolomé A (2005) Sociedad de la información y cambio educativo. In: Dias P, Freitas C (eds.) Actas da IV Conferência Internacional de Tecnologias de Informação e Comunicação na Educação, Challenges 2005. Centro de Competência Nónio Século XXI da Universidade do Minho, Braga, pp. 17-41

10. Paavola S, Lipponen L, Hakkarainen K (2002) Epistemological foundations for CSCL: A comparison of three models of innovative knowledge communities. http://www.newmedia.colorado.edu/cscl/228.html

11. Dias P (2004) Desenvolvimento de objectos de aprendizagem para plataformas colaborativas. In: Barrientos X, Zúñiga V, Ortiz J, Isaías L, Guerra S, Garza R, Cantú M, Hinojosa S (eds.) Actas do VII Congreso Iberoamericano de Informática Educativa. Universidad de Monterrey, Monterrey, pp. 3-12

12. Duart J, Sangrà A (2000) Formación universitaria por medio de la web: un modelo integrador para el aprendizaje superior. In: Duart J, Sangrà A (eds.) Aprender en la Virtualidad. Editorial Gedisa, Barcelona, pp. 23-49

13. Anderson T (2004) Toward a theory for online learning. In: Anderson T, Elloumi $\mathrm{F}$ (eds.) Theory and practice of online learning. Athabasca University, Athabasca, pp. 33-60

14. Zabalza M (2003) Competencias docentes del profesorado universitario: Calidad y desarrollo profesional. Narcea, Madrid

15. Crook C (1998) Ordenadores y aprendizaje colaborativo. Ediciones Morata, Madrid

16. Moore M (1989) Editorial: Three types of interaction. The American Journal of Distance Education vol 3, 2: 1-6. http://www.ajde.com/Contents/vol3_2.htm\#editorial

17. Anderson T (2003) Modes of interaction in distance education: Recent developments and research questions. In: Moore MG, Anderson WG (eds.) Handbook of distance education. Lawrence Erlbaum Associates, Mahwah, New Jersey, pp. 129-144 